\title{
Craniofacial modifications in children with habitual snoring and obstructive sleep apnoea: a case-control study
}

\author{
M. Zucconi*, A. Caprioglio ${ }^{+}$, G. Calori**, L. Ferini-Strambi*, A. Oldani*, C. Castronovo*, S. Smirne*
}

Craniofacial modifications in children with habitual snoring and obstructive sleep apnoea: a case-control study. M. Zucconi, A. Caprioglio, G. Calori, L. Ferini-Strambi, A. Oldani, C. Castronovo, S. Smirne. C) ERS Journals Ltd 1999.

ABSTRACT: Habitual snoring and obstructive sleep apnoea in children, which are frequently associated with adenotonsillar hypertrophy, may begin early in life and in relation with orocraniofacial features. The aim of this study was to detect the presence of early bone craniofacial modifications in young children with a long history of habitual snoring.

Twenty-six habitually snoring children (mean age $4.6 \mathrm{yrs}$ ) were studied by nocturnal portable recording or diurnal polysomnography, cephalometry and orthodontic evaluation. A comparison of cephalometric findings was made between the studied group and 26 age-matched children (mean age 5.1 yrs) with no history of snoring or respiratory problems during sleep.

The cephalometric analyses showed a significant increase in craniomandibular intermaxillar, lower and upper goniac angles with a retroposition and posterior rotation of the mandible (high angle face) and a reduction in the rhinopharynx space caused by higher thickness of adenoids in habitually snoring children compared with controls. Cross-bites and labial incompetence as well as daytime symptoms and familiarity for habitual snoring were found in most of the studied group of snorers compared with controls.

The results indicate that upper airway obstruction during sleep is associated with mild but significant cephalometric and craniofacial modifications in children complaining of habitual snoring. Whether this skeletal conformation is genetically determined or influenced by the early onset of habitual snoring remains to be assessed. Eur Respir J 1999; 13: 411-417.

In children with upper airway (UA) obstruction, usually due to enlarged adenoids and tonsils, habitual snoring and obstructive sleep apnoea (OSA) are frequent [1-3] and may begin early in life $[4,5]$. Craniofacial abnormalities, occurring in syndromes that include nasal obstruction, micrognatia, short cranial base, midfacial hypoplasia, together with macroglossia, hypotonia and obesity are other predisposing conditions leading to UA obstruction during sleep [1-3]. However, in the majority of children without evident craniofacial morphological abnormalities the peak incidence of habitual snoring and OSA is between 3 and 6 yrs, which is the age of prominence of lymphoid tissue [6]. Generally, adenotonsillectomy resolves the UA obstruction but the persistence or reappearance of snoring and OSA later in life, after surgery at a prepubertal age, suggests that craniofacial modifications may be precocious and related to genetic or environmental factors $[7,8]$. The aims of this study were to evaluate children with OSA associated with tonsillar hypertrophy and to perform standard measures of the face, comparing these data with those of a group of children without OSA or tonsillar hypertrophy. The finding of a significant difference in facial features between the two groups would imply either that this is acquired, secondary to chronic airway obstruction,
Sleep Disorders Center, *Dept of Neurology and **Epidemiology Unit, State University and IRCCS H San Raffaele, Milan, Italy. ${ }^{+}$Dept of Orthodontics, School of Dentistry, University of Insubria, Varese, Italy.

Correspondence: M. Zucconi

Sleep Disorders Center

Dept of Neurology

San Raffaele Hospital

Via Stamira D'Ancona 20

20127 Milan

Italy

Fax: 390226433394

Keywords: Cephalometry

children

obstructive sleep apnoea

snoring

Received: May 181998

Accepted after revision October 121998 or that it is a congenital mild craniofacial anomaly which predisposes to UA obstruction $[9,10]$.

In young children with a long history of habitual snoring the presence of early craniofacial modifications was verified by cephalometry and by an orthodontic approach. The goal was reached comparing craniofacial features of habitual snoring children with a sample of children with no history of snoring or related sleep respiratory problems. Three different methods of cephalometric analysis were used: one for skeletal evaluation (Gianni analysis) and two for soft tissue evaluations, the Linder-Aronson analysis, which implies a geometrical reconstruction of the landmarks (a more objective evaluation), and the Solow analysis, in which the landmarks are identified by the analyser (a more subjective evaluation) [11].

\section{Materials and methods}

Twenty-six children complaining of habitual snoring and suspected of having OSA were studied (age 4.6 \pm 1.5 yrs (mean $\pm \mathrm{SD})$, range 3-8.7 yrs). Most of this group was referred to the authors' sleep laboratory from an ear, nose, and throat (ENT) department for adenotonsillar surgery 
pre-evaluation. None of the cases had previously been submitted to ENT surgery and informed consent was obtained from the parents before the children entered the study. Children with the following characteristics were excluded from the study: chronic illness, use of decongestant preparations, acute UA infections, acute otitis media, dysmorphic or craniofacial syndromes, as well as Down's syndrome or muscular dystrophy. The studied group represented a typical sample of habitual snoring children and not a subsample of difficult and atypical cases. The control group consisted of 26 age-matched children (age 5.1土 0.5 yrs, range 4-7 yrs) selected from consecutive patients referred to an orthodontic department for routine evaluation, without craniofacial anomalies and with a negative history of habitual and chronic snoring and sleep-related respiratory problems. The age matching was obtained by grouping the children from $3-4.5,4.6-6$ and $>6$ yrs.

All patients and controls underwent a sleep-orientated interview together with their parents, in the presence of the same physician (M. Zucconi). The interview consisted of a structured pattern of questions concerning anthropometric variables, familiarity, allergy, parental smoking, ENT symptoms, snoring, reported apnoea, quality, quantity and time schedule of nocturnal/diurnal sleep, and diurnal symptoms (e.g. oral breathing, irritability, failure to thrive, recurrent UA infections, diurnal sleepiness). The questionnaire has previously been validated and used for an epidemiological study on snoring in children aged 3-6 yrs [12]. Children were considered habitual snorers when the parents answered "always" or "often" to the question on snoring (always and often=yes, sometimes and never= no). Snoring children were evaluated by a diurnal polysomnography of at least $3 \mathrm{~h}$ of consecutive sleep (including at least a 30-min period of rapid eye movement (REM) sleep) after partial (3-4 h) sleep deprivation. In the case of insufficient sleep or REM sleep, nocturnal ambulatory monitoring of snoring and oxygen desaturation events (Madaus electronic snoring ambulatory monitoring; MESAM IV, MAP, Martinsried, Germany) was carried out [13]. MESAM IV data (collected in 12 cases) were only considered to confirm the correct inclusion of the children in the habitual snoring group, but were not included in the final results session. The recorded snoring amount was considered by studying the automatic detection of snoring percentage $(>20 \%)$ or visually scored epoch-by-epoch according to the criteria of BEARPARK et al. [14]. The parents of control subjects underwent a detailed interview about their children's sleep to exclude the presence of snoring. If any doubts appeared from the history, the control child was excluded from the study.

Respiration and other polysomnographic findings were evaluated according to the international criteria $[15,16]$. Obstructive apnoea was defined as the absence of airflow with persistent respiratory effort for at least $10 \mathrm{~s}$; mixed apnoea episodes were counted together with obstructive events because these usually begin as central and end in obstruction. Obstructive hypopnoea was defined as a $50 \%$ reduction in airflow because no standardized methods to identify hypopnoea in children have been defined. Apnoeic events were not separated from hypopnoeic events when they were associated with oxygen desaturations or arousals. Central apnoea, which occurred after gross body movements or after sighs, was not considered as a pathological finding [16]. Desaturation events were considered if there was more than a $4 \%$ decrease in the oxygen saturation level. A microphone taped above the larynx and connected to the polygraph was used to record snoring sounds directly onto paper. The following respiratory variables were considered: apnoea-hypopnoea index (AHI), number of desaturation events (DE) $>4 \%$, mean low arterial oxygen saturation $\left(\mathrm{Sa}_{\mathrm{a}} \mathrm{O}_{2}\right) \%$ and lowest (nadir) $\mathrm{Sa}_{\mathrm{a}} \mathrm{O}_{2} \%$. The respiratory data refer to the diurnal polysomnography, which was carried out in all 28 habitually snoring children. After informed consent had been obtained from the parents, cases and controls, underwent lateral cephalometry for the evaluation of UA and anatomical landmarks of the head and face, according to a standard technique [17].

A lateral projection of the face and skull was obtained using a Gendex Ortholalix (Gendex Corp Des Plaines, IL, USA) radiographic apparatus; the film was used with a radiographic screen and placed in a box of dimensions of $24 \times 30 \mathrm{~cm}$. The radiographic exposition was made according to the different physical constitution of the patient. All cephalograms were obtained with the head in a natural position, with the subject standing and using a mirror eye reference position [17]. The techniques of Solow et al. [18] (fig. 1) and LinDER-Aronson [19] (fig. 2) were used for the evaluation of UA, and the Gianni school cephalometric analysis [20] was applied to evaluate bone structure landmarks with angle and distance parameters (fig. 3). The method consists of recognizing the landmarks by visual analysis and digitizing the measures of angles and distances using computerized software (HP, Villefontaine, France) in combination with a digitizer method (Digilite, Imola, Italy). All three analyses are valid; the LinderAronson technique is the most complex but methodologically the most correct.

All of the lateral cephalograms were traced four times by the same operator (A. Caprioglio), during different periods, to exclude errors in method. Cephalometric measurements, analysed by repeated-measures analysis of variance (ANOVA) (4V-BMDP) [21] in each group, did not show any significant differences among repeated measures in

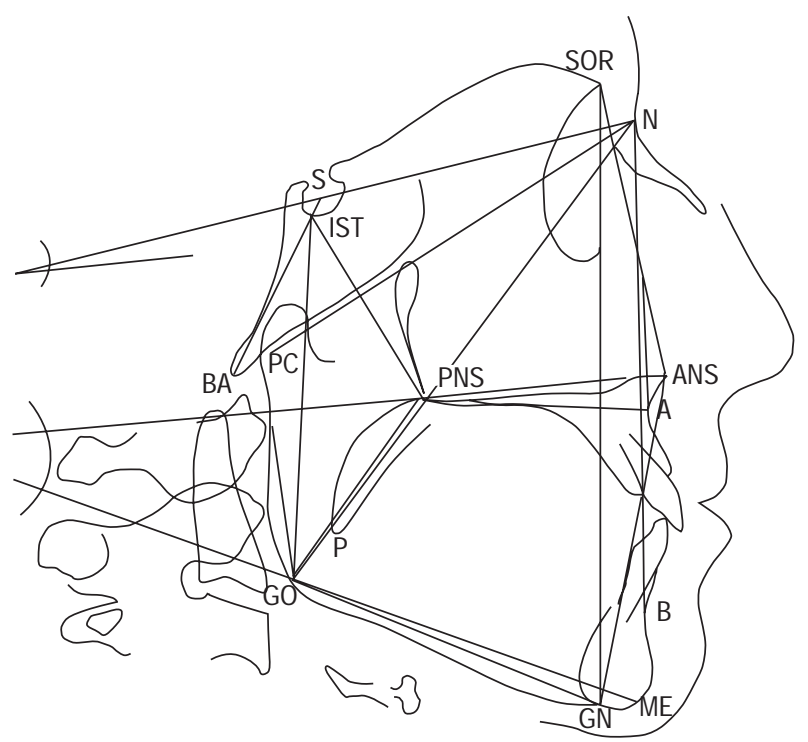

Fig. 1. - Cephalometric analysis according to the technique of Solow et al. [18]. For definitions see table 1. 


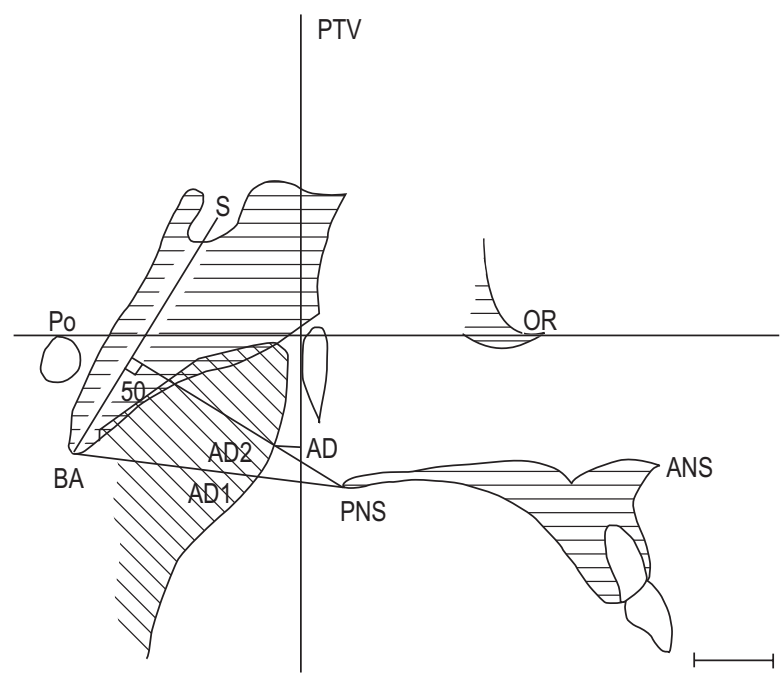

Fig. 2. - Cephalometric analysis according to the technique of LINDERAronson et al. [19]. For definitions see table 1. (Scale bar=20 mm.)

tracing bony structure points on the radiographs. The means of the coefficients of intrasubject variation varied from a minimum of 0.55 (ANB) or 0.66 (N-Go-Gn) to a maximum of 10.62 (P2) or 12.79 (ANB). Therefore, in order to reduce the error in the method, means of parameters have been used. Comparisons between the two groups were made by the Mann-Whitney U-test and correlation analysis was performed to investigate the correlation between the severity of snoring and OSA and the cephalometric parameters. In order to identify which cephalometric variables best discriminate between the cases and the controls, a stepwise logistic regression was performed (LR-BMDP) [21]. Only variables that resulted in significant differences between the two groups at univariate analysis were included in the model.

\section{Definition of cephalometric variables}

Gianni school of analysis. Angle from sella to nasion to subspinale point (SNA), angle from sella to nasion to

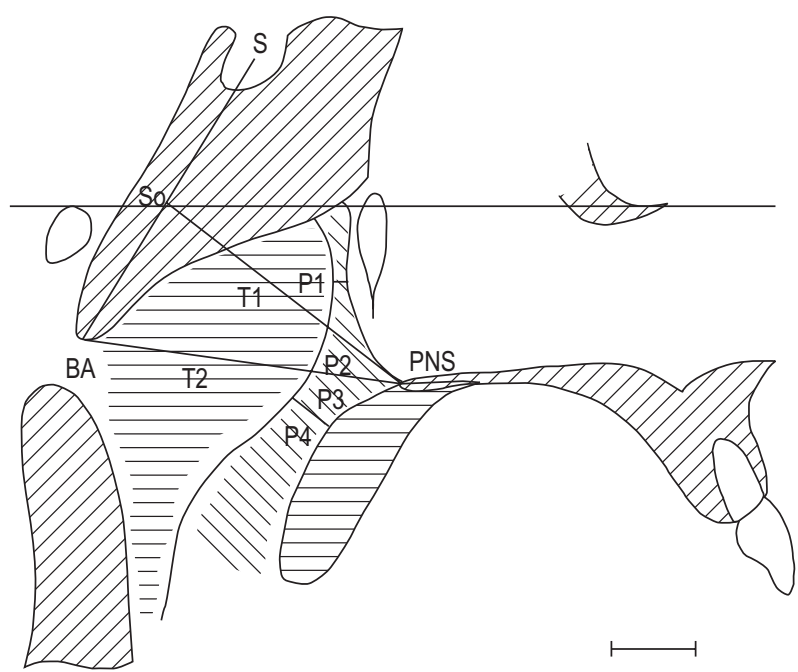

Fig. 3. - Cephalometric analysis according to the Gianni school of analysis [20]. For definitions see table 1. (Scale bar=15 mm.) supramentale point (SNB), difference between SNA and SNB (ANB), angle of inclination of the mandible (SNGo-Gn), intermaxillar angle (PNS ANS-Go-Gn), occlusal plane-mandibular plane angle (P.occl-Go-Gn), upper goniac angle (PC-Go-Gn), lower goniac angle (N-Go$\mathrm{Gn}$ ) and angle from basion to sella to posterior nasal spine (BA-S-PNS) (table 1).

Linder-Aronson analysis. Linear distance between PNS and the nearest point of adenoids along the line BAPNS (AD1), linear distance between PNS and the nearest point of adenoids along the line passing in PNS and perpendicular to the line BA-S (AD2), linear distance between the nearest point of adenoids and a point along PTV, placed $5 \mathrm{~mm}$ upon the point of insertion of PTV and the line BA-PNS (PTV-AD) (table 1).

Solow analysis. Least linear distance of the adenoids from the posterior wall of maxillary sinus (P1), linear distance between PNS and SO that is the middle point of the line BA-S (P2), linear distance between PNS and the adenoids along the line BA-PNS (P3), least linear distance between the highest point of velum palatinum and adenoids (P4), thickness of adenoids along the line PNS-SO (T1), thickness of adenoids along the line PNSBA (T2) (table 1).

All of the children underwent an orthodontic clinical examination, including the analysis of the dental class and the evaluation of cross-bite. Cross-bite was defined as an abnormal relationship of teeth to the opposing teeth, in which normal buccolingual or labiolingual relationship are reversed, and lip incompetence as a gap between the related upper and lower lips because of a vertical hard and soft tissue imbalance.

\section{Results}

The age of onset of snoring was $22.7 \pm 14.1$ months (mean \pm SD) while the mean age of apnoea onset, as reported by parents, was $34.7 \pm 11.3$ months. The majority of the snorers showed daytime forced oral respiration (96.2\%), while about $20 \%$ of the snoring children had a failure to thrive. In about $81.2 \%$ of the sample daytime irritability was reported. Moreover, in the $70 \%$ of the snoring children there was a positive familial history for habitual snoring (considering only the first-degree siblings). Control children did not show any daytime symptoms and a familiarity for habitual snoring was not reported.

Respiratory results revealed a mean AHI of 11.2 \pm 9.6 , DE 75.8 774.5 , mean low $\mathrm{Sa}_{\mathrm{a}} \mathrm{O}_{2} \% 90.3 \pm 3.8$ and lowest $\mathrm{Sa}_{\mathrm{a}, \mathrm{O}_{2}} \% 81.1 \pm 12.3$. Forty-five per cent had an AHI $>5$ episodes $\cdot h$ of sleep ${ }^{-1}$. Eighty-four percent had a lowest $\mathrm{Sa}_{\mathrm{a}} \mathrm{O}_{2}$ $<90 \%$, however, only two habitually snoring children had a severe OSA syndrome. Snoring sounds were recorded in $>50 \%$ of the recording epochs in $70 \%$ of the children.

Cephalometric bone data are summarized in table 2: a significant increase in craniomandibular (SN-Go-Gn) and intermaxillar (PNS-ANS-Go-Gn) angles indicated a high angle face in the snoring group with a posterior rotation of the mandible (increase in P.occl-Go-Gn). Moreover, the increase in both upper and lower goniac angles (PC-Go-N and N-Go-Gn) caused an important retroposition and postinclination of the mandibular plane, indicating a future vertical growth. The bony nasopharynx, as indicated by 
Table 1. - Definitions of cephalometric measurements

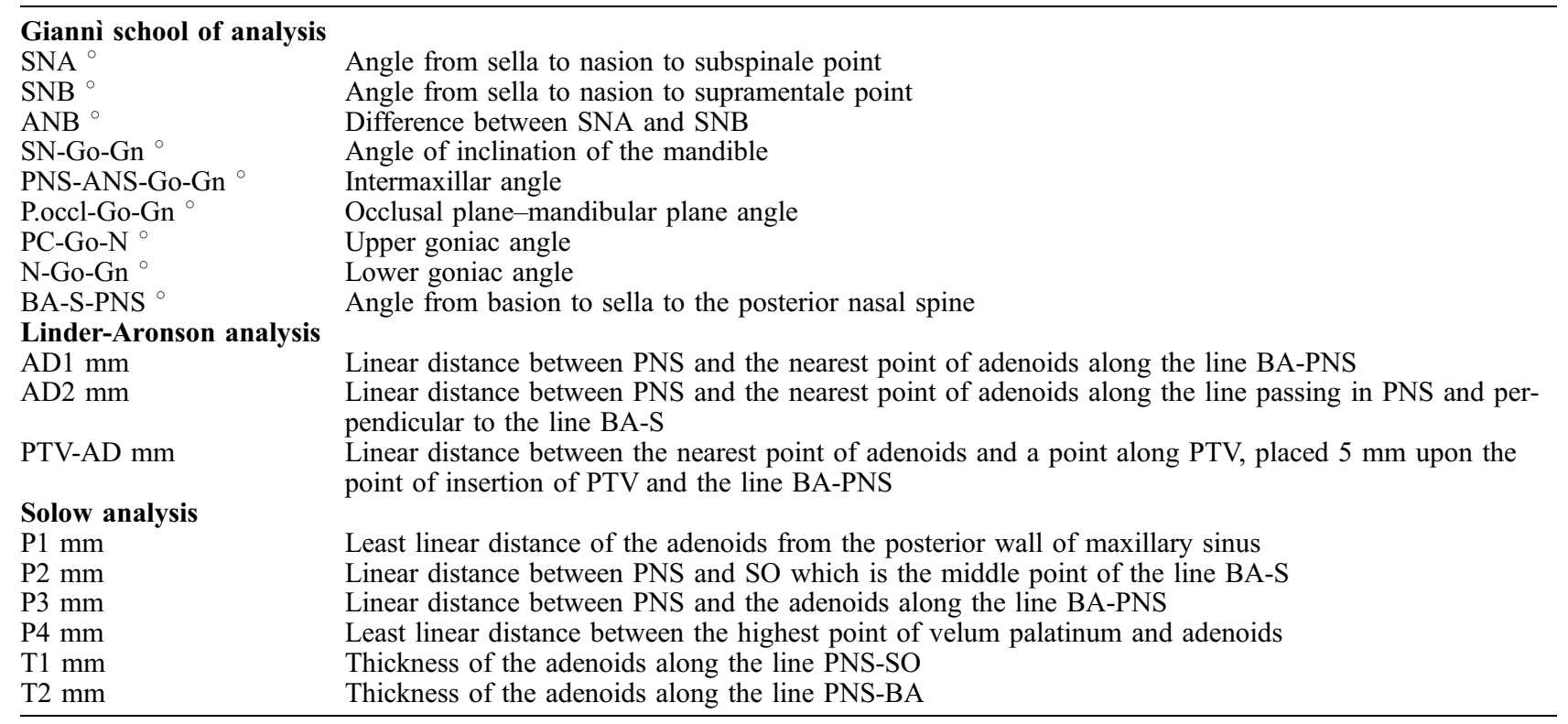

the angle BA-S-PNS, was significantly increased in habitual snorers.

The Solow and Linder-Aronson analyses (table 3) indicated a general significant reduction in the virtual space of the rhinopharynx, showing low cephalometric values of the soft tissues (higher thickness of adenoids).

Figures 4 and 5 show cephalometry of a classical snoring child and a nonsnoring control, respectively.

Regarding the orthognatodontic examination, the presence of cross-bite and of labial incompetence was found in 52 and $69 \%$ of the snoring children, respectively, but in none of the controls.

Correlation analysis showed a low but significant relationship among SNA $(r=0.47, p<0.05)$, SNB $(r=0.46, p<$ 0.05 ) and age of snoring onset, i.e. the earlier the children started to snore, the lower the correlation between SNA and SNB. Moreover, the upper goniac angle (AR-Go-N) correlated with AHI $(\mathrm{r}=0.53, \mathrm{p}<0.01)$ and $\mathrm{DE}(\mathrm{r}=0.54$, $\mathrm{p}<0.01)$, but not with $\mathrm{Sa}_{2} \mathrm{O}_{2} \%$ parameters.

The variables that best discriminated between cases and controls were: Sn-Go-Gn ( $\mathrm{p}<0.001)$, PNS-ANS-Go-Gn ( $\mathrm{p}<$ $0.001)$, P.occl-Go-Gn ( $\mathrm{p}<0.001)$ and PC-Go-Gn $(0.001)$ for Giannì cephalometric analysis and AD1 $(\mathrm{p}<0.001)$, AD2

Table 2. - Cephalometric results by Giannì school of analysis in snorers and controls

\begin{tabular}{|c|c|c|c|}
\hline Measure & $\begin{array}{c}\text { Snorers } \\
(n=26)\end{array}$ & $\begin{array}{c}\text { Controls } \\
(n=26)\end{array}$ & $\mathrm{p}$-value \\
\hline $\mathrm{SNA}^{\circ}$ & $81.1 \pm 3.4$ & $80.8 \pm 1.3$ & NS \\
\hline $\mathrm{SNB}^{\circ}$ & $75.1 \pm 3.9$ & $76.1 \pm 1.7$ & NS \\
\hline $\mathrm{ANB}^{\circ}$ & $5.9 \pm 1.9$ & $4.8 \pm 1.3$ & NS \\
\hline SN-Go-Gn ${ }^{\circ}$ & $39.7 \pm 5.1$ & $34.7 \pm 2.3$ & 0.006 \\
\hline PNS-ANS-Go-Gn ${ }^{\circ}$ & $31.7 \pm 5.3$ & $20.1 \pm 3.4$ & 0.001 \\
\hline P.occl-Go-Gn ${ }^{\circ}$ & $17.7 \pm 4.3$ & $13.8 \pm 2.1$ & 0.01 \\
\hline PC-Go-N ${ }^{\circ}$ & $56.9 \pm 5.4$ & $49.7 \pm 2.9$ & 0.001 \\
\hline N-Go-Gn ${ }^{\circ}$ & $74.7 \pm 6.6$ & $70.7 \pm 3.2$ & 0.001 \\
\hline BA-S-PNS ${ }^{\circ}$ & $63.9 \pm 3.9$ & $60.0 \pm 4.0$ & 0.001 \\
\hline
\end{tabular}

Values are expressed as mean \pm SD. For definitions of measures see table 1 . $(p<0.001)$, PTV-AD $(p<0.001)$ and T1 $(p<0.001)$ for Linder-Aronson and Solow analysis. From a practical point of view the best variable for proper discrimination between habitual snorers and normal children was AD1, representing the space between the posterior nasal spine and the beginning of the adenoidal protrusion; this corresponds to the P3 measures for the Solow analysis.

\section{Discussion}

The results indicate a morphological craniofacial type in children with habitual snoring and OSA. Skeletal results showing a high angle and the increase in both upper and lower goniac angles, together with the orthodontic findings, clearly demonstrated that UA obstruction is related to mild but significant craniofacial modifications, shown not only by clinical evaluation but also by cephalometry. Nevertheless, the bony nasopharynx was increased with respect to controls (increase in BA-S-PNS in the snorer group), there was a reduction in the nasal posterior airway space because of the mechanical obstruction due to the enlarged adenoids. The values from Linder-Aronson and

Table 3. - Cephalometric results by Linder-Aronson and Solow analyses in snorers and controls

\begin{tabular}{lrrc}
\hline Measure & \multicolumn{1}{c}{$\begin{array}{c}\text { Snorers } \\
(\mathrm{n}=26)\end{array}$} & $\begin{array}{c}\text { Controls } \\
(\mathrm{n}=26)\end{array}$ & p-value \\
\hline AD1 mm & $12.9 \pm 5.4$ & $18.4 \pm 2.3$ & 0.007 \\
AD2 mm & $9.9 \pm 3.9$ & $14.4 \pm 2.0$ & 0.001 \\
PTV-AD mm & $3.4 \pm 3.3$ & $7.8 \pm 1.8$ & 0.001 \\
P1 mm & $1.6 \pm 2.0$ & $6.2 \pm 1.6$ & 0.001 \\
P2 mm & $9.8 \pm 3.9$ & $15.4 \pm 2.3$ & 0.001 \\
P3 mm & $12.9 \pm 5.4$ & $18.4 \pm 1.4$ & 0.005 \\
P4 mm & $2.9 \pm 1.8$ & $7.8 \pm 2.6$ & 0.001 \\
T1 mm & $19.2 \pm 5.0$ & $15.4 \pm 2.1$ & NS \\
T2 mm & $29.9 \pm 4.3$ & $22.8 \pm 2.2$ & 0.008 \\
\hline
\end{tabular}

Values are expressed as mean \pm SD. For definitions of measures see table 1 . 


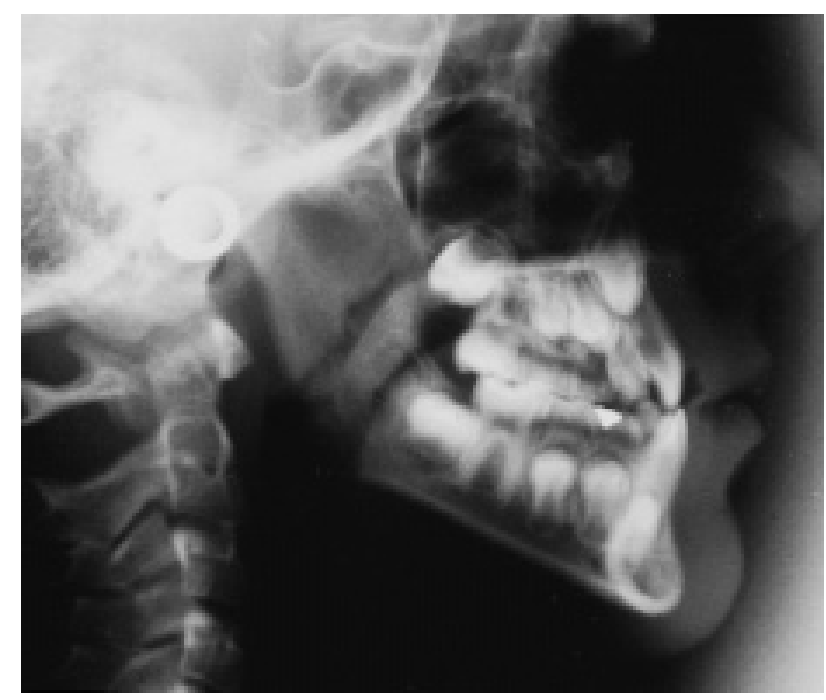

Fig. 4. - Cephalometry of a typical snoring child, showing the thickness of adenoids and the inferior and posterior rotation of the mandible.

Solow tracings showed short cephalometric measurements for soft tissues landmarks. Moreover, the modification of facial skeletal morphology may also be responsible for the abnormalities as the pharyngeal musculature is related to the bony structure.

This study has demonstrated that the snoring and OSA children are skeletal open-bite subjects who showed increased values of the anterior facial height and a vertical reduction in the posterior facial height. The high values of the craniomandibular angle (SN-Go-Gn) and the angle between the occlusal plane and the mandibular plane (P.occlGo-Gn) reveal the posterior rotation of the mandible, as well as the angle between the maxillary plane and the mandibular plane (PNS-ANS-Go-Gn). This latter result is important to show that the studied group had growth towards an open vertical relationship between the jaws compared with the controls. The increase in both upper and lower goniac angles causes an important retroposition and postinclination of the mandibular plane, which can be used

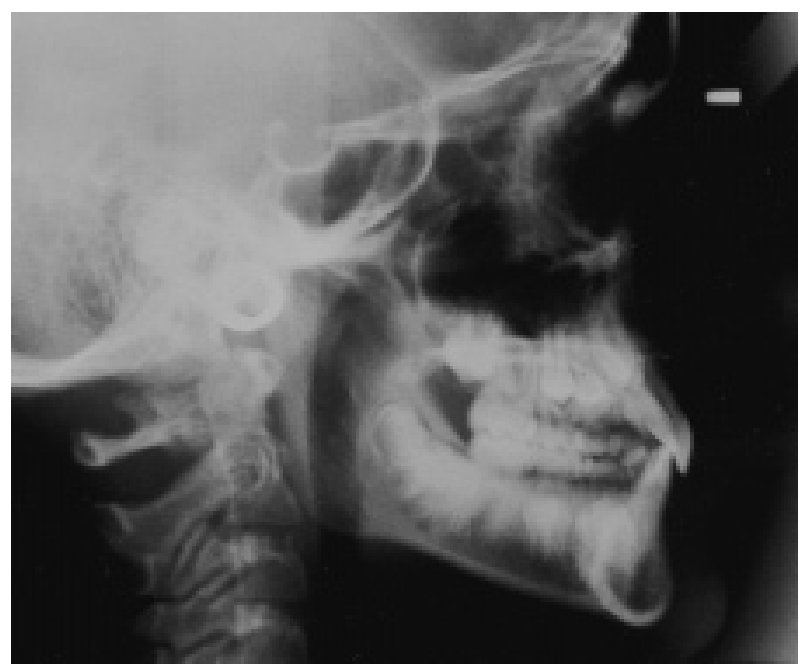

Fig. 5. - Cephalometry of a control nonsnoring child, showing the normal position of the mandible and the absence of mechanical obstruction of the rhinopharynx. to indicate future vertical growth, as shown by other authors $[19,22]$. This cephalometric study confirms individual clinical reports that minor craniofacial anomalies are present in snoring children. This condition can be favoured by the continuous increased respiratory effort that these children must make during the night (and, in the most severe cases, also during the day) in order to overcome UA obstruction as a consequence of enlarged adenoids and tonsils [23]. The forced oral daytime respiration, present in most of the children, is the daytime consequence of this condition.

Regarding the skeletal class, the authors did not find a common retroposition of the mandible (II skeletal class) as described in previous studies [24, 25], suggesting that this craniofacial class is not essential to the development of UA obstruction in children. The orthodontic clinical examination revealed posterior cross-bites caused by a reduced growth of the maxillary bone after continuous oral breathing, and anterior open-bite with lip incompetence, owing to an abnormal forward position of the tongue.

Craniofacial morphology and modifications in children with UA obstruction during sleep are well known, not only in patients affected by pathologies at high risk for OSA, as with craniofacial synostosis associated with midfacial hypoplasia, micrognatia, hypotonia or obesity, but also in children with adenotonsillar hypertrophy [26]. A recent retrospective study of 411 children referred to a sleep centre for suspected UA obstruction during sleep indicated a small triangular chin, retroposition of the mandible, a long face and a high-arched hard palate as typical clinical orocraniofacial features of the syndrome [27]. However, few studies considered cephalometric analysis to define the role of craniofacial morphology and adenotonsillar size in the determination of UA obstruction and its consequences. Cephalometry is a useful and accepted diagnostic tool in adult OSA patients for the evaluation of soft tissue and bone UA measures during wakefulness and for selecting candidates for surgical treatment [28, 29]. In children, however, it is not routinely used for ethical reasons and few normative data, especially for the 1-5-yr-old category, are available [30]. Only one recent Japanese study compared cephalometric results in children with OSA and in age matched controls [31]. Despite the large number of patients and controls evaluated, cephalometric analysis was focused only on some adenotonsillar measures and a few skeletal landmarks. Their results are similar to those of the present study as concerns the adenoids mechanical obstruction of rhinopharynx, but the reduction of maxillary and mandible protrusion in young and elderly children was more pronounced than in the present study. However, the correlation between early start of snoring and decreased SNA and SNB angles may indicate a genetic predisposition to snoring when poor mandible prognatism and reduced maxillary growth are present, as also suggested by the Japanese Study [32], although they did not look at the projected growth pattern or the orthodontic examination.

Regarding the clinical and sleep-respiratory data, the present results showed the early starting of signs of UA obstruction during sleep (snoring) and confirmed the frequent daytime oral respiration of habitually snoring children, as suggested by others [4, 5]. Moreover, about 30\% of children did not have continuous snoring or respiratory events during sleep, despite the complaint and the positive 
answer regarding habitual and chronic snoring from the parent's interview. This is not surprising when one considers the night-to-night variability in mild-to-moderate OSA children and the limitations of the methodology used to record sleep respiratory variables [32]. Daytime polysomnography or monitoring by a portable device (MESAM IV) were chosen to overcome problems of limited compliance with the full nocturnal polysomnography in young children. The authors are aware of the limitations in sensibility and specificity of these types of recording procedure and that no validation studies are available showing the reliability of daytime polysomnography or portable recording in children with OSA [2]. However, the purpose of this study was not to record respiratory events in habitually snoring children or to evaluate the severity of the syndrome, but, rather, to verify the objective presence of snoring in children with a positive answer to the questionnaire on habitual snoring versus the nonsnoring controls.

A more recent normative study on sleep, respiration and cephalometry in children was carried out, but the data concerned older children (mean age 13 yrs) and young adults and, therefore, are not comparable with the present results [33].

This study did not determine whether the craniofacial and cephalometric modifications of snoring children are genetically determined or environmentally influenced. There is some evidence that sleep-disordered breathing and OSA aggregate significantly in families [34]. Part of this risk may be explained by disproportional craniofacial anatomy, which is considered as a strong indicator of inherited features that influence UA size [35]. The present finding of a positive familial history for habitual snoring in the majority of the snoring children seems to support this theory.

It is likely that both genetic and environmental factors, through a complex, interaction, determine the position of the mandible, change the mandibular morphology, with restriction of forwards growth of the maxilla and mandible, and redirect it in a more caudal direction $[6,36]$.

In conclusion, in this case-control study of children aged 4-9 yrs, habitual snoring, independent from the associated obstructive apnoea, was significantly related to an increase in the craniomandibular and intermaxillar angle (high angle face), upper and lower goniac angles and posterior rotation of the mandible. Mechanical obstruction of the rhinopharynx, cross-bites and labial incompetence indicated that upper airway obstruction influences the posture of the tongue, face and teeth, leading to craniofacial modifications. Only serial studies would demonstrate whether this is acquired (secondary to obstruction with change in the position of the tongue and pharynx) or whether there is a genetic predisposition.

Acknowledgements. The authors thank D. Bizzozero, A. Massimo and G. Lecciso, EEG Technologists of the Sleep Disorders Center, for their support and skill in sleep-respiratory recordings.

\section{References}

1. Guilleminault C. Obstructive sleep apnea syndrome in children. In: Guilleminault C, ed. Sleep and its Disorders in Children. New York, Raven Press, 1987; pp. 213-224.

2. Gaultier C. Obstructive sleep apnea syndrome in infants and children: established facts and unsettled issues. Tho$\operatorname{rax} 1995$; 50: 1204-1210.

3. Carrol JL, Loughlin GM. Obstructive sleep apnea syndrome in infants and children. Clinical features and pathophysiology. In: Ferber R, Kryger M, eds. Principles and Practice of Sleep Medicine in the Child. Philadelphia, PA, WB Saunders, 1995; pp. 163-192.

4. Davidson Ward SL, Marcus CL. Obstructive sleep apnea in infants and young children. J Clin Neurophysiol 1996; 13: 198-207.

5. Zucconi M, Ferini-Strambi L, Pestalozza G, Tessitore E, Smirne S. Habitual snoring and obstructive sleep apnea syndrome in children: effects of early tonsil surgery. Int $J$ Pediatr Otorhinolaryngol 1993; 26: 235-243.

6. Solow B. Upper airway obstruction and facial development. In: Davidovitch Z, ed. The Biological Mechanisms of Tooth Movement and Craniofacial Adaptation. Columbus, OH, Ohio State University College of Dentistry, 1992; pp. 571-579.

7. Guilleminault C, Partinen M, Praud JP, Quera Salva MA, Powell N, Riley R. Morphometric facial changes and obstructive sleep apnea in adolescents. J Pediatr 1989; 114 : 997-999.

8. Pestalozza G, Tessitore E, Bellotto R, Zucconi M. Tonsil surgery in heavy snoring young children. In: Galioto GB, ed. Tonsils: a Clinically Oriented Update. Adv Otorhinolaryngol, Vol. 47. Basel, , Karger, 1992; pp. 251-259.

9. Viva E, Stefini S, Annibale G, Pedercini M, Zucconi M, Ferini-Strambi L. Aspect of prevention of obstructive sleep apnea syndrome in developing children. In: Galioto GB, ed. Tonsils: a Clinically Oriented Update. Adv Otorhinolaryngol, Vol. 47. Basel, , Karger, 1992; pp. 284-289.

10. Zucconi M, Caprioglio A, Curci C, Ferini-Strambi L, Oldani A, Smirne S. Craniofacial modifications in children with habitual snoring and obstructive sleep apnea: preliminary results. In: Sadé J, ed. Infections in Childhood. Amsterdam, Elsevier, 1994; pp. 322-326.

11. Solow B, Siersback-Nilsen S. Growth changes in head posture related to craniofacial development. Am J Orthod 1986; 59: 132-140.

12. Castronovo V, Zucconi M, Nosetti L, et al. Habitual snoring among children aged 3 to 6 years: an epidemiological study with objective measurement of snoring and oxygen saturation. Sleep 1998; 21: Suppl., 51.

13. Stoohs R, Guilleminault C. MESAM 4: an ambulatory device for the detection of patients at risk for obstructive sleep apnea syndrome (OSAS). Chest 1992; 101: 12211227.

14. Bearpark H, Elliot L, Grunstein R, et al. Snoring and sleep apnea: a population study in Australian men. Am J Respir Crit Care Med 1995; 151: 1459-1465.

15. Marcus CL, Omlin KJ, Basinki DJ, et al. Normal polysomnographic values for children and adolescents. Am Rev Respir Dis 1992; 146: 1235-1239.

16. Rosen CL, D'Andrea L, Haddad GG. Adult criteria for obstructive sleep apnea do not identify children with serious obstruction. Am Rev Respir Dis 1992; 146: 1231-1234.

17. Athanasiou AE, Papadopoulos M, Lagoudakis M, Goumas P. Cephalometric assessment of craniocervical angulation, pharyngeal relationship, soft palate dimensions, hyoid bone and tongue position. In: Davidovitch $\mathrm{Z}$, ed. The Biological Mechanisms of Tooth Movement and Craniofacial Adaptation. Colombus, $\mathrm{OH}$, Ohio State University College of Dentistry, 1992; pp. 203-216.

18. Solow B, Siersbaek-Nielsen S, Greve E. Air adequacy, head posture and craniofacial morphology. Am J Orthod 1984; 86: 214-223. 
19. Linder-Aronson S. Adenoids: their effect on mode of breathing and nasal air flow, and their relationship to characteristics of the facial skeleton and the dentition. Acta Otolaryngol 1970; 265: 1-132.

20. Giannì E. La nuova ortognatodonzia. Padova, Italy, Piccin, 1980.

21. Dixon WJ. BMDP: Biomedical Computer Program. Berkeley, CA, University of California Press, 1990.

22. Lowe AA, Bookstein FL. Airway/tongue interaction in obstructive sleep apnea. Bio Mech Tooth Mov Cranio Adapt 1992; 7: 513-522.

23. Stoohs R, Guilleminault C. Obstructive sleep apnea syndrome or abnormal upper airway resistance during sleep? J Clin Neurophysiol 1990; 7: 83-92.

24. Bresolin D, Shapiro GG, Shapiro PA, et al. Facial characteristics of children who breath through the mouth. Pediatrics 1984; 73: 622-625.

25. Bacon WH, Krieger J, Turlot JC, Stierle JL. Craniofacial characteristics in patients with obstructive sleep apnea syndrome. Cleft Palate J 1988; 25: 374-378.

26. Solow B, Ovesen J, Nielsen PW, Wildschiodtz G, Tallgren A. Head posture in obstructive sleep apnea. Eur $J$ Orthod 1993; 15: 107-114.

27. Guilleminault C, Pelayo R, Leger D, Clerk A, Bocian RCZ. Recognition of sleep-disordered breathing in children. Pediatrics 1996; 98: 871-882.

28. Zucconi M, Ferini-Strambi L, Palazzi S, Orena C, Zonta $\mathrm{S}$, Smirne S. Habitual snoring with and without obstruc- tive sleep apnoea: the importance of cephalometric variables. Thorax 1992; 47: 157-161.

29. Zucconi M, Ferini-Strambi L, Palazzi S, Curci C, Cucchi E, Smirne S. Craniofacial cephalometric evaluation in habitual snorers with and without obstructive sleep apnea. Otolaryngol Head Neck Surg 1993; 109: 1007-1013.

30. Sarnas KV, Solow B. Early adult changes in the skeletal and soft-tissue profile. Eur J Orthod 1980; 2: 1-12.

31. Shintani T, Asakura K, Kataura A. Adenotonsillar hypertrophy and skeletal morphology of children with obstructive sleep apnea syndrome. Acta Otolaryngol 1996; 523: Suppl., 222-224.

32. Marcus CL, Kenns TG, Ward SL. Comparison of nap and overnight polysomnography in children. Pediatr Pulmonol 1992; 13: 16-21.

33. Acebo C, Millman RP, Rosenberg C, Cavallo A, Carskadon MA. Sleep, breathing and cephalometric in older children and young adults. Part I - Normative values. Chest 1996; 109: 664-672.

34. Redline S, Tishler PV, Tosteson TD, et al. The familial aggregation of obstructive sleep apnea. Am J Respir Crit Care Med 1995; 151: 682-687.

35. Guilleminault C, Partinen M, Hollman K, Powell N, Stoohs R. Familial aggregates in obstructive sleep apnea syndrome. Chest 1995; 107: 1545-1551.

36. Guilleminault C, Stoohs R. Chronic snoring and obstructive sleep apnea syndrome in children. Lung 1990; Suppl., 912-919. 